\title{
The Role of Carvacrol as Active Compound of Essential Oils in Diabetes
}

\author{
Roonak Amiri ${ }^{1}$ and Mohsen Akbari*2 \\ ${ }^{1}$ Department of Chemical Engineering, Faculty of Engineering, Iran \\ ${ }^{2}$ Young Researchers and Elite Club, Kermanshah Branch, Iran
}

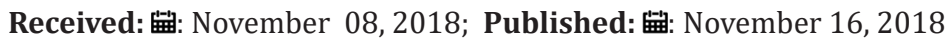

*Corresponding author: Mohsen Akbari, Young Researchers and Elite Club, Kermanshah Branch, Islamic Azad University, Kermanshah, Iran

Abstract

Diabetes is known as a severe disease that is associated with faulted carbohydrate, protein, and fat metabolism. Challenging stressful lifestyle and inappropriate dietary habits prolong individual to diabetes. Natural compounds such as medicinal plants and their derivations, i.e. extracts, essential oils and active compounds are broadly used to prevent and treatment of diabetes. Carvacrol as active compound of essential oils is known to have antibacterial, antioxidant, anti-inflammatory activities that can be used for treatment of diabetes and infected wounds. In the mini-review article, we will introduce carvacrol and view some previous studies and present recommendations for application of carvacrol in diabetes disease.

Keywords: Carvacrol, Diabetes, Hyperglycemia

\section{Introduction}

Diabetes has been identified as a severe disease that is created through autoimmune insulin deficiency [type 1] or insulin resistance [type 2]. Hyperglycemia and/or hypoinsulinemia can have serious effects on body status [1]. Diabetes is associated with deficiencies in carbohydrate, protein and fat metabolism that occurs with an absolute or relative lack of insulin [hypoinsulinemia] [2]. Diabetes not only influences macromolecule metabolism but also affects the serum concentration of liver enzymes and lipids in patients [3-5]. Synthetic anti-diabetic drugs can have dangerous side effects such as hypoglycemic coma and liver and kidneys disorders. Researchers are trying to find efficient and safer antidiabetic drugs to be an important area for research [6]. Dietary factors can have a key role in the development of various human diseases. Studies have shown that diets rich in fruits, herbs and spices decrease risk of diseases. Natural phytogenic structures are extensively applied in the production of pharmaceuticals substances. The use of biologically active plant substances, especially in the European countries, Japan, and the USA has been recently interested [7].

Essential oils or volatile oils have been defined as aromatic liquids extracted by distillation from different plant parts. Compounds and aromas of essential oils are categorized into 2 major groups including terpene hydrocarbons and oxygenated compounds. Some oxygenated compounds common and known in plant essential oils are including phenols such as thymol, eugenol, carvacrol, chavicol, etc. Structure of some known phenols is shown in Figure 1. Active compounds of essential oils are known to have antibacterial, antioxidant, anti-inflammatory activities that can be used for treatment of diabetes and infected wounds. In this minireview, we describe carvacrol as active compound of essential oils and studies conducted on diabetes.

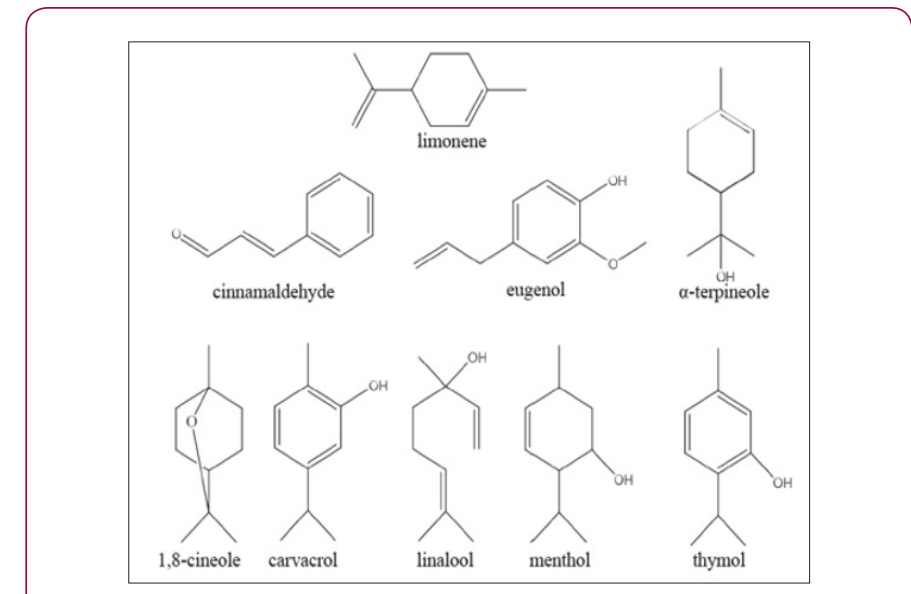

Figure 1: Chemical structure of some major components of essential oils. 


\section{Carvacrol}

Carvacrol is a monoterpenic phenol that is broadly found in some essential oils especially in family Labiatae. It was extensively found in Origanum, Satureja, Thymbra, Thymus, and Corydothymus species [8]. It is known to have some pharmacological properties such as anti-inflammatory [9], antioxidant [8], antitumor [10], and antimicrobial [11] activity. It is also known to activate the peroxisome proliferator-activated receptor and suppresses COX-2 inflammation [12]. Since diabetes is associated with fatness and metabolic syndrome, thus decreased fat may help to improve the condition in diabetic patients. It has been reported that carvacrol decreases body weight in the high-fat diet -fed mice because it prevent adipocyte differentiation in mouse pre-adipocytes [13]. In one study, Ezhumalai et al. showed that administration of Carvacrol decreased glucose, insulin, glycosylated hemoglobin, aspartate aminotransferase, alanine aminotransferase, alkaline phosphatase, and gammaglutamyl transpeptidase. Bayramoglu et al. [15] showed that administration of carvacrol slightly decreased the serum concentration of glucose and cholesterol, alanine aminotransferase, aspartate aminotransferase and lactate dehydrogenase in diabetic rats.

In other study, Deng et al. [16] reported that administration of carvacrol decreased oxidative stress, also prevented the tumor necrosis factor- $\alpha$-induced NF- $\kappa B$ signaling way and also decreased caspase- 3 activity in diabetic rats. They advised to use carvacrol in treatment of diabetes because of antioxidative and anti-inflammatory properties. Wounds in diabetes are known as big challenge in diabetes. Gunal et al. [17] showed that topical administration of carvacrol healed wound through modulating in inflammatory system and gene expression. It may speed up wound healing in diabetic wounds.

\section{Conclusion}

In sum, carvacrol can improve conditions in patients with diabetes due to antioxidant and anti-inflammatory properties. It can be used as a natural phytogenic compound in treatment of diabetes. It may be also used in treatment of diabetic wounds. We recommend carvacrol for treatment of diabetes and diabetic wounds.

\section{References}

1. Hoybergs YM, Biermans RL, Meert TF (2008) The impact of bodyweight and body condition on behavioral testing for painful diabetic neuropathy in the streptozotocin rat model. Neurosci Lett 436: 13-18.

2. Schmatz R, Perreira LB, Stefanello N, Mazzanti C, Spanevello R, et al (2012) Effects of resveratrol on biomarkers of oxidative stress and on the activity of delta aminolevulinic acid dehydratase in liver and kidney of streptozotocin-induced diabetic rats. Biochimie 94: 374-383.

3. Juskiewicz J, Zdunczyk Z, Jurgonski A, Brzuzan Ł, Godycka- Kłos I, et al. (2008) Extract of green tea leaves partially attenuates streptozotocininduced changes in antioxidant status and gastrointestinal functioning in rats. Nutr Res 28: 343-349.

4. Sepodes B, Maio R, Pinto R, Marques C, Mendes-do-Vale J, et al. (2004) Tempol, an intracelullar free radical scavenger, reduces liver injury in hepatic ischemia-reperfusion in the rat. Transplant Proc 36(4): 849-853.

5. Bi W, Cai J, Xue P, Zhang Y, Liu S, et al. (2008) Protective effect of nitronyl nitroxide-amino acid conjugates on liver ischemia-reperfusion induced injury in rats. Bio org Med Chem Lett 18(6): 1788-1794.

6. Ali MM, Agha FG (2009) Amelioration of streptozotocininduced diabetes mellitus, oxidative stress and dyslipidemia in rats by tomato extract lycopene. Scand J Clin Lab Invest 69(3): 371-379.

7. Jafari B, Rezaie A, Ebadi A, Ghiamirad M, Ahmadizadeh C, et al. (2011) Evaluation of medicinal plant oil (Teucrium polium) in diets of broilers. J Appl Biol Sci 12: 583-586.

8. Kirimer N, Baser KHC, Tumen G (1995) Carvacrol rich plants in Turkey. Chem Nat Comp 31(1): 37-42.

9. Berger JP, Akiyama TE, Meinke PT (2005) PPARs: therapeutic targets for metabolic disease. Trends Pharmacol Sci 26(5): 244-251.

10. Kallistratos G, Evangelou A, Agnantis N, Fasske E, Karkabounas S, et al. (1994) Enhancement of the antineoplastic effect of anticarcinogens on benzo(a)pyrene-treated Wistar rats, in relation to their number and biological activity. Cancer Lett 82: 153-165.

11. Evangelou A, Kalpouzos G, Karkabounas S, Liasko R, Nonni A, et al. (1997) Dose-related preventive and therapeutic effects of antioxidantsanticarcinogens on experimentally induced malignant tumors in Wistar rats. Cancer Lett 115: 105-111.

12. Hotta M, Nakata R, Katsukawa M, Hori K, Takahashi S, et al. (2010) Carvacrol, a component of thyme oil, activates PPAR and suppresses COX-2 expression. J Lipid Res 51: 132-139.

13. Cho S, Choi Y, Park S, Park T (2012) Carvacrol prevents dietinduced obesity by modulating gene expressions involved in adipogenesis and inflammation in mice fed with high-fat diet. J Nutr Biochem. 23: 192201.

14. Ezhumalai M, Radhiga T, Viswanathan Pugalendi K (2014) Antihyperglycemic effect of carvacrol in combination with rosiglitazone in high-fat diet-induced type 2 diabetic C57BL/6J mice. Mol Cell Biochem 385: 23-31.

15. Bayramoglu G, Senturk H, Bayramoglu A, Uyanoglu M, Colak S, et al. (2014) Carvacrol partially reverses symptoms of diabetes in STZinduced diabetic rats. Cytotechnol 66: 251-257.

16. Deng W, Lu H, Teng J. Carvacrol attenuates diabetes-associated cognitive deficits in rats. J Mol Neurosci 51(3): 813-819.

17. Gunal MY, Heper AO, Zaloglu N (2014) The effects of topical carvacrol application on wound healing process in male rats. Phcog J 6: 10-14. 


\section{ISSN: 2574-1241}

DOI: $10.26717 / B J S T R .2018 .11 .002054$

Mohsen Akbari. Biomed J Sci \& Tech Res

(C) (1) This work is licensed under Creative

Submission Link: https://biomedres.us/submit-manuscript.php

$\begin{array}{ll}\text { BIOMEDICAL } & \text { Assets of Publishing with us } \\ \text { RESEARCHES } & \text { - Global archiving of articles } \\ \text { - Immediate, unrestricted online access }\end{array}$

